\title{
VARIAÇÃO LINGUÍSTICA NOS LIVROS DIDÁTICOS DE LÍNGUA PORTUGUESA DA EDUCAÇÃO DE JOVENS E ADULTOS
}

Katiuscia da Silva Santos ${ }^{1}$

\section{RESUMO:}

Este artigo faz uma análise do livro didático de português da coleção Tempo de Aprender, $6^{\circ}$ ao $9^{\circ}$ ano, das classes de Educação de Jovens e Adultos, livros pertencentes ao Programa Nacional do Livro Didático para a Educação de Jovens e Adultos - PNLDEJA de 2011. Com o objetivo de investigar a abordagem de variação linguística esta pesquisa procurou relacionar as três formas de estudo da variação linguística, apontadas por Dionísio e Bezerra (2005), nos livros didáticos de língua portuguesa. Para tanto os procedimentos metodológicos utilizados foram fundamentados num constructo teórico da sociolinguística, e baseados nos estudos de Bortoni-Ricardo (2004, 2005), Callou (2007) Marcuschi (2001), Rocha (2013), Bagno, Stubbs e Gagné (2002) e principalmente Dionísio e Bezerra (2005) e Bagno (2007), com discussões sobre a variação linguística, seus conceitos e pressupostos. Por meio das análises, pode ser verificado que os livros didáticos avaliados abordam a variação linguística com bastantes limitações no que se refere aos conceitos dos teóricos utilizados.

PALAVRAS CHAVES: Variação Linguística, Livro Didático, EJA.

\begin{abstract}
:
This article is an analysis of the textbook Portuguese Collection Time Learning, 6th to 9th grade, the class of Youth and Adults, books belonging to the National Textbook Program for the Education of Youth and Adults - PNLDEJA 2011. With the objective to investigate the approach of linguistic variation this research sought to relate the three forms of the study of linguistic variation, mentioned by Dionísio and Bezerra (2005), in Portuguese language textbooks. For both the methodological procedures used were based on a theoretical construct of sociolinguistics, and based on studies Bortoni-Ricardo (2004, 2005), Callou (2007) Marcuschi (2001), Rocha (2013), Bagno, Stubbs and Gagné (2002) and especially Dionísio and Bezerra (2005) and Bagno (2007), with discussions on linguistic variation, it's concepts and assumptions. Through the analysis, it can be verified that the textbooks evaluated approach to linguistic variation with many limitations with regard to the theoretical concepts used.
\end{abstract}

Keyworlds: Linguistic Variation, Textbook, EJA.

\footnotetext{
${ }^{1}$ Mestranda em Educação e Contemporaneidade (UNEB). Especialista em Linguística (UNEB). PósGraduanda em Educação do Campo (IFBaiano). Graduada em Letras (UNEB) Professora da Educação Básica. E-mail: katymssantos@gmail.com.
} 


\section{CONTEXTUALIZAÇÃO}

É comum, numa mesma língua, existirem variações que revelam características das especificidades regionais, etárias, de gêneros e classe sociais que caracterizam a sua heterogeneidade. Contudo, é perceptível que essa heterogeneidade é vista de forma deturpada por alguns profissionais da educação, o que ocasiona, em alguns casos, na não aceitação de outras variantes. E nas salas da Educação de Jovens e Adultos (EJA) é comum encontrar sujeitos, que em sua maioria, são falantes de formas peculiares e que pertencem às classes desprestigiadas socialmente, neste aspecto a escola assume o importante papel de resgatar esse caráter heterogêneo dos falares e o Livro Didático (LD) desempenha um papel auxiliar importante.

Portanto este artigo traz uma reflexão sobre estudos realizados com os Livros Didáticos de Língua Portuguesa (LDLP) que foram apresentados a Universidade do Estado da Bahia para obtenção de título de Especialista em Linguística, investigação esta, que adotou a pesquisa bibliográfica, e objetivou principalmente investigar de que maneira a Variação Linguística (VL) era abordada nos LDLP oferecidos MEC no Programa Nacional do Livro Didático para a Educação de Jovens e Adultos (PNLDEJA) de 2011 para o Ensino Fundamental II, à luz dos estudos Bortoni-Ricardo (2004, 2005), Callou (2007), Marcuschi (2001, 2005), Rocha (2013), Bagno, Stubbs e Gagné (2002), Bentes e Mussalin (2006 e 2008) e principalmente por Dionísio e Bezerra (2005) e Bagno (2007).

\section{EDUCAÇÃO DE JOVENS E ADULTOS}

A escola voltada para o "povo", população menos favorecida, e, por conseguinte os adultos trabalhadores, foi forjada pela necessidade das industrias, a posteriore da revolução industrial, tendo em vista que os trabalhos nas indústrias necessitavam de mão de obra com conhecimentos básicos para operacionalizar algumas máquinas. E apenas após quase 450 anos de colonização/exploração/imposição, começa-se a ensaiar um sistema educativo próprio brasileiro. 
Durante o período da Primeira Guerra Mundial Anísio Teixeira ${ }^{2}$ analisou que a oferta das matrículas não foi suficiente, porque necessitavam de prédios e professores para satisfazer as necessidades da população. Com o fim da guerra, aumentou o interesse pela educação elementar, elevando a necessidade de lutar contra o analfabetismo dos adultos. Quando assumiu a direção da educação no Distrito Federal, modificou os conteúdos dos “cursos populares", para os cursos de adultos. Desde então, desenvolveram outros sistemas de aceleração educacional nos estados, especialmente no sul do país. A luta contra o analfabetismo sempre foi motivada por muitas campanhas tanto governamentais quanto das culturas populares.

No início dos anos 60 há a publicação da primeira Lei de Diretrizes e Bases da Educação Nacional, publicada em 20 de dezembro de 1961, que instituiu a obrigatoriedade da educação e passando a definir e regularizar o sistema educacional brasileiro.

Neste mesmo período inicia-se um levante tanto por campanhas governamentais, como pelos movimentos sociais e culturais, para enfrentar aos altos índices de analfabetismo brasileiro, que circundava os $40 \%$. Foi neste contexto que surgiram então alguns programas de caráter popular como o Movimento de Educação de Base (MEB), Centro Popular de Cultura (CPC) e o Movimento de Cultura Popular (MCP) idealizado Por Paulo Freire. No final dos 60, Freire escreve seu mais célere livro, Pedagogia do Oprimido, que o inicia dedicando "Aos esfarrapados do mundo, e aos que nele se descobrem e, assim descobrindose, com eles sofrem, mas, sobretudo, lutam”. (Fávero, Paiva, Freire, 1987, p. 12). Durante muito tempo a educação não formal ficou marginalizada.

Outros fatores importantes a serem destacados são: a Lei 5692/71 e o Parecer 699/72 do Conselho Nacional de Educação que regulamentaram os cursos 'supletivos' seriados e os exames de certificação, para atender uma população que necessitava de comprovação escolar para o trabalho (CARVALHO, 2010). Contudo esta oferta primeiramente temporária se converteu em ensino permanente. Nesta proposta, o currículo e a matriz de ensino seguiam a organização do ensino seriado, porém compactado, não tendo qualquer especificidade ao jovem e ao adulto.

Na década de 90, impulsionado pelas políticas educacionais de trabalho e emprego que houve a proliferação de cursos voltados para o atendimento das demandas de qualificação e requalificação profissionais de jovens e adultos trabalhadores, mesmo assim

\footnotetext{
${ }^{2}$ Entre 1932 e 1935 assumiu a direção da educação no Distrito Federal (substituído Fernando de Azevedo) e modificou os conteúdos dos "cursos populares" e criando ainda os "cursos de continuação e aperfeiçoamento. (Carvalho 2010, p.17)
}

Revista Educação e Ciências Sociais, Salvador, v.1, n.1, 2018. 
não dissociada da educação básica. De acordo com a Lei de Diretrizes e Bases, LDB no 9.394/96, em seu Art. 37

$\S 1^{\circ}$ da educação brasileira, os jovens e adultos, que não puderam efetuar o estudo na idade regular, terão assegurados gratuitamente pelos sistemas de ensino mediante cursos e exames, oportunidades educacionais apropriadas, consideradas suas características, seus interesses, condições de vida e de trabalho mediantes

Outro fator que merece atenção neste processo é prática educativa de alguns professores que por falta de conhecimento e formação específica, infantilizam o conteúdo na crença de que os estudantes não possuem as habilidades e a experiência para acompanhar as propostas ou, às vezes, creem que estes incapazes de produzir devido à falta de tempo e à carga horária excessiva. Nesta perspectiva, Freire (1997, p.116)

Tão importante quanto ele, o ensino dos conteúdos, é o meu testemunho ético ao ensiná-los. É a docência com o que o faço. É a preparação científica revelada sem arrogância, pelo contrário, com humildade. É o respeito jamais negado ao educando, a seu saber de "experiência feito" que busco superar com ele. Tão importante quanto o ensino dos conteúdos é a minha coerência na classe. A coerência entre o que digo o que escrevo e o que faço.

As pessoas aprendem ao longo da vida (Freire,1996), em seus trabalhos e atividade ocupacionais cotidianas propiciam uma aquisição de saberes, e assim, uma interação com as pessoas e o mundo. Esses saberes informais, apesar de diferentes, não são menos importantes que os conteúdos formais da educação escolarizada. Na educação há interlocução de saberes sempre em reconstrução através das aprendizagens no mundo, e das vivências dos sujeitos singularizados, vivências que se ressignificam nos espaços e tempos sociais dos distintos âmbitos linguísticos e do convívio das alteridades distintas" (MARQUES, 2002).

A escola por vez tem um importante papel de incentivar e reconhecer os falares desses sujeitos, sendo necessário perceber o papel do educador frente a esse estudante jovem e adulto que chega a sala de aula cheio de conhecimento de mundo (com teorias suas próprias teorias, explicações e hipóteses).

\section{LÍNGUA PORTUGUESA E VARIAÇÃO LINGUÍSTICA}


É comum se ouvir falar da uniformidade da Língua Portuguesa, porém como mencionou Ilari e Basso (2006) essa visão de uniformidade é, em grande parte, um mito, que, de certa forma, foi contribuída pelo 1)nacionalismo; 2) visão limitada de fenômeno linguístico, levando em conta apenas a língua culta e 3) pela insensibilidade à variação, contrapartida do fato de que naturalmente os falantes se adaptam a diferentes contextos de fala. Uma língua que não seja suscetível as influências do tempo (variação diacrônica), das regiões (variação diatópica), dos estratos de população, da escolarização, (variação diastrática) e pelas influencias referentes ao diversos meios de uso e veículos de comunicação (variação diamésica) é inimaginável. Para Ilari e Basso (ibidem, p.195):

Portanto, variação existe, quer gostemos disso, quer não. Mas há muita gente para quem esse fato é um problema: essas pessoas se sensibilizam com a variação diastrática e tendem a achar que falar uma variedade diferente da variedade padrão é um problema sério para a sociedade e para quem o faz, talvez um vício, talvez um crime, talvez uma manifestação de inferioridade.

As variações (diacrônica, diatópica, diastrática e diamésica) ocorrem, e a ideia equivocada de uniformidade do Português deixa as formas de variações esquecidas e marginalizadas. Estudar essas variações sobre a língua falada, observada, descrita, e analisada em seu contexto real é o objetivo da sociolinguística. Segundo Silva (2003) o estudo da variação como modelo de análise linguística, proposta de adicionar componentes sociais ao estudo linguístico, a "Teoria da Variação Linguística" ou "Sociolinguística Quantitativa”, teve seu ápice a partir dos estudos do norte-americano William Labov, em meados da década de 60, no Canadá e nos Estados Unidos. É um modelo teóricometodológico que teve como objetivo principal sistematizar a variação e a heterogeneidade linguística.

A Variação é inerente a língua e a sociolinguística percebe essa variedade como uma qualidade constitutiva do fenômeno linguístico, sendo que, qualquer tentativa de aprender somente o invariável representa uma redução na compreensão do fenômeno linguístico (BENTES e MUSSALIN 2008).

\subsection{O ensino de Língua Materna}


A língua é uma forma de comunicação convencionada política e territorialmente por um grupo de pessoas com o intuito da comunicação e interação social. Apesar de cada grupo adotar certa língua como comunicação, é comum perceber variações características das especificidades regionais, etárias, de gêneros e classes sociais que caracterizam a sua heterogeneidade.

Porém, alguns profissionais da educação não admitem outras variantes, nem essa heterogeneidade, acreditando ser a Língua Portuguesa uma unidade que deve ser difundida única e exclusivamente na forma padrão, devendo as outras variedades, que muitos acreditam não terem valor, serem esquecidas e excluídas do processo educativo.

Nas classes de EJA, essa situação ainda se agrava mais, visto que são turmas heterogêneas formadas por sujeitos jovens e adultos; e que na maioria dos casos são falantes de várias variantes desprestigiadas socioeconomicamente, e que veem no ambiente escolar uma perspectiva de reconhecimento e valorização de seus direitos e experiências de vida. Contudo, o que se percebe é uma escola, que, em muitos aspectos, ignora o caráter heterogêneo da língua e não consegue resgatar nem aproveitar a sua riqueza para melhorar o seu ensino, acontecendo, assim, a priorização única da norma padrão em detrimento de outras variedades que estão presentes na sala de aula e na vida dos alunos da EJA.

\subsection{Variação e ensino}

O profissional da educação, principalmente o de língua portuguesa, deve reconhecer e propiciar aos educandos o contato com as variantes linguísticas, proporcionando a conscientização das diferenças. Bortoni-Ricardo $(2005)^{3}$ relembra as palavras de Freire, afirmando que os professores não devem criticar ou reprimir um aluno que fale coisas como “nós chegemu”, ao iniciar a discussão sobre a sociolinguística aplicada ao ensino de Língua Portuguesa, ação que foi chamada pelo prefaciador Dr. Francisco Gomes de $\operatorname{Matos}^{4}$ como sociolinguisticamente humanizadora.

O ensino de língua deve oportunizar o (re)conhecimento aos diferentes falares. Para Callou (2007, p. 17) "não existe uma norma única, mas sim uma pluralidade de normas, normas distintas segundo os níveis sociolinguísticos e as circunstâncias de comunicação”.

\footnotetext{
${ }^{3}$ Declaração encontrada no início do seu livro Nós Cheguemu na escola e agora? ao mencionar as palavras de Paulo Freire, quando foi Secretário de Educação do Estado de São Paulo.

${ }^{4}$ Linguista, Professor emérito da UFPE e Prefaciador do livro Nós Cheguemu na escola e agora?
} 
Ela propõe uma reavaliação do lugar da norma padrão, o que pressupõe considerar a variação e tal norma "como produto de uma hierarquização de múltiplas formas variantes possíveis" (ibdem). Neste aspecto Bortoni-Ricardo (2005, p.15) acredita que:

A escola não pode ignorar as diferenças sociolinguísticas. Os professores e, por meio deles, os alunos tem que estar bem conscientes de dizer duas ou mais maneiras de dizer a mesma coisa. E mais, que essas formas alternativas servem a propósitos comunicativos distintos e são recebidos de maneira diferenciada pela sociedade.

E, por conseguinte, a escola possui importante papel de desenvolver a sensibilidade de perceber as várias variantes e de prepará-lo para se adequar às diversas situações comunicativas. Mas o que se percebe é que há uma tendência em tratar a oralidade e a escrita através de uma perspectiva dicotômica, como pensa Marcuschi (2001, p.28) "A perspectiva da dicotomia estrita tem o inconveniente de considerar a fala o lugar do erro e do caos gramatical, tomando a escrita como o lugar da norma e do bom uso da língua. Seguramente, trata-se de uma visão a ser rejeitada".

É na escola, especificamente na sala de aula, que o estudante pode reflexionar sobre as várias variantes e o seu papel como falante. Assim a escola, o professor e o livro didático desempenham papeis importantes na mediação desse aprendizado, pois precisam direcionar o olhar sobre o que é considerado 'erro', definindo critérios para transformá-lo numa possibilidade de aprendizado, e não num sinônimo de incompetência linguística e exclusão. Para Bortoni-Ricardo (2004), erros de português são simplesmente diferenças entre as variedades da língua, de um lado a usada no lar, com uma predominância da cultura oral permeada por relações de afeto e informalidade; em oposição à cultivada na escola que prioriza única e exclusivamente o letramento.

Diante dessa realidade, é importante identificar de que forma livros didáticos de língua portuguesa da EJA abordam a variação linguística? Que crenças transmitem? Quais orientações linguísticas esse instrumento sugere ao professor?

\subsection{O ensino de Língua Materna, Variação e EJA}

Ao relacionar o ensino de língua materna e Educação de Jovens e Adultos, é importante lembrar as palavras de Mattos e Silva (2004) ao citar que ensino é um trabalho de criação e não obrigação mecânica, sendo importante que qualquer indivíduo que entre na

Revista Educação e Ciências Sociais, Salvador, v.1, n.1, 2018. 
escola, já é "senhor de sua língua, na modalidade oral ", e, assim sendo se constitui num trabalho de enriquecimento do potencial linguístico.

Porém, tradicionalmente, a escola vê o educando como tábula rasa (Mattos e Silva, 2004), não considerando seus saberes linguísticos, em nome de levá-los a dominar a norma padrão culta idealizada. O que se opõe as ideias freirianas de uma educação emancipadora.

Por ser a escola o espaço de se reflexionar sobre as várias variantes, e por se tratar de estudantes de classe de EJA, é indispensável a utilização de metodologia e procedimentos que contextualizem as aulas envolvendo e aproveitando o conhecimento comum dos alunos. Como diz Callou (2007, p.27):

Se qualquer falante já possui uma gramática internalizada - sistemas de regras e princípios universais - ao ingressar na escola, ele deve desenvolver a sua competência comunicativa de tal modo que possa "utilizar melhor" a sua língua em todas as situações de fala e escrita, isto é, possa ser capaz de refletir sobre a capacidade linguística que ele já possui e domina no nível intuitivo, mas sobre a qual nunca antes se tinha debruçado para analisar o funcionamento.

Porém, não é fácil a contextualização do ensino de língua portuguesa com a realidade dos sujeitos, mostrando as diferenças entre a variação na fala, suas interferências na escrita, e esclarecer as diferenças entre o ato de falar e de escrever. Mesmo porque, também se espera que, além do desenvolvimento linguístico, deve haver a preparação para a cidadania e para o trabalho a partir do reconhecimento das diferentes formas de falar e escrever e das interferências da oralidade no letramento, considerando, sobretudo, a variação como um fenômeno natural inerente à língua.

\section{O LIVRO DIDÁTICO DE LÍNGUA PORTUGUESA:}

O MEC, iniciou o compromisso com a qualidade dos LD através da criação de uma comissão para definir critérios para a sua avaliação. Essa comissão, criada 1993, subordinou a compra LD ao Programa Nacional do Livro Didático (PNLD), aos livros que fossem inscritos e aprovados por uma avaliação prévia. Desde então os LD veem sendo pesquisados e são pontos de debates e polêmicas, e o Livro Didático de Português (LDP) vem sendo 
também objetivo dessas pesquisas e discussões. A partir de 1996 o MEC passou a adotar para as escolas os livros inscritos no PNLD.

Contudo, só a partir da Criação do PNLDEJA em 2009 é que pode haver a avaliação dos livros específicos para esses sujeitos, como ficou definida na primeira política pública voltada para esse público, as Diretrizes Curriculares Nacionais para Educação de Jovens e Adultos, de 2 de julho de 2000.

O PNLDEJA 2011 inaugurou a avaliação de material especifico para os jovens e adultos tendo como critério de avaliação quatro blocos para cada obra. Segundo Rocha (2013, p.2):

O primeiro bloco de critérios tinha por meta identificar se o material em tela respeitava as bases legais, as diretrizes educacionais definidas pelo Estado para a Educação Básica em geral e para a EJA em particular. O segundo bloco de critérios dizia respeito aos aspectos relacionados, particularmente, ao livro do aluno... O terceiro bloco de critérios se referia aos elementos presentes no Manual do Educador. Finalmente, o quarto bloco de critérios estava voltado à análise dos aspectos gráficos das obras.

Para atender aos critérios do primeiro bloco a obra deveria respeitar a Constituição, as diretrizes Nacionais, a LDB, o Estatuto da Criança, o Estatuto do Idoso, as leis que regem as minorias étnicas e os deficientes físicos. Além disso, esse critério ainda previa que a obra não poderia apresentar preconceito de qualquer natureza (linguístico, gênero, étnico, social, político).

Um tópico importante para teoria educacional de linguagem tem de ser os livros que são usados na escola, e estes em geral tiveram grande avanço nas questões da incorporação dos novos conceitos de educação linguística (Bagno, Stubbs e Gilles (2002) Sobre a língua dos LD (ibdem) os autores indicam que "Parece evidente que existem relações entre as formas de linguagem nos livros didáticos, as instituições em que elas são usadas, o controle social e intelectual que eles sustentam e as práticas pedagógicas que eles pressupõe.”

Por ter sido criado recentemente, em comparação com o PNLD, o PNLDEJA, faz levantar alguns questionamentos sobre o ensino de Variação Linguística, onde estão e como são ensinadas. Para análise da Dionísio e Bezerra (2005) aponta três formas norteadoras do estudo da varação nos Livros Didáticos de Português: (i) abordagem em unidade especifica no livro, (ii) abordagem em questões mínimas inseridas na análise textual, (iii) em seções sobre reflexão sobre a língua. As autoras ainda expõem que: 
A formulação de conceitos se processa mediante, basicamente, duas propostas de atividades, que são: (i) a apresentação de um texto sobre VL acompanhado por perguntas de compreensão e (ii) na utilização de um texto com VL, seguido por perguntas de compreensão e de identificação e reescritura de VL. (2005, p.79)

$\mathrm{Na}$ crítica da forma como é tratada a variação pelos LD, Possenti (apud DIONÍSIO e BEZERRA, 2005) diz que não se trata de substituir os manuais de análise sintática por capítulos de variação, com questões artificiais, e sim levar em consideração o próprio conhecimento do aluno e confrontá-lo com a variedade padrão, esse é material mais que suficiente para levar ao aluno reconhecer a sua variedade linguística como uma variedade entre outras tendo consciência de sua identidade linguística e se dispor a observar as variedades que não domina.

\subsection{Análise do Livro Didático}

A investigação científica é uma ação racional e reflexiva que reconhece a realidade e permite que o investigador trate de maneira crítica realizando certas ações que possibilite estudar e reflexionar os contextos para poder responder suas indagações. Para realizar tal investigação, ou melhor, "interpretação", foi necessário uma pesquisa bibliográfica, fundamental para oferecer subsídio metodológicos para análise de dados e dos Livros Didáticos do PNLDEJA 2011, subsidiando teoricamente pelos princípios de Dionísio e Bezerra, com o intuito de possibilitar a verificação da VL nas edições, trazendo assim informação sobre o avanço da incorporação dos novos conceitos de educação linguística.

O livro didático escolhido como objeto de análise e da abordagem da VL foi o da disciplina de Língua Portuguesa, da coleção Tempo de Aprender da Editora IBEP, enviado e avaliado pelo MEC e distribuído pelo Fundo Nacional de desenvolvimento da Educação (FNDE), através do PNLDEJA 2011, utilizado na Educação de Jovens e Adultos da escola Joao Pereira de Pinho, localizada na zona rural do município de Araci, à $30 \mathrm{Km}$ da sede.

Esta coleção é organizada em quatro volumes multidisciplinares, formada por 7 disciplinas (Língua Portuguesa, Matemática, História, Geografia, Ciências Naturais, Língua Estrangeira Moderna - Inglês, e Artes). Cada volume é dividido em duas unidades, que por sua vez, são subdivididas em 4 capítulos. A coleção foi construída a partir de um trabalho 
que busca a articulação entre vários conteúdos, partindo de temas comuns, procurando relacionar os conteúdos a partir de temas, conceitos estudados, procedimentos e habilidades desenvolvidas. Sendo assim, cada área (disciplina) é composta por oito unidades com temas comuns, que correspondem a todo o ensino fundamental II.

Ao realizar a pesquisa foram encontradas algumas dificuldades que limitaram o campo investigado, já que, a priori esperava-se fazer uma análise comparada dos Livros Didáticos escolhidos pelos PNLDEJA de 2011 e enviados às escolas de Araci, com fundamentação teórica especifica para a variação linguística nos livros didático da EJA.

Mas, ao fazer a busca bibliográfica não foi encontrada nenhuma bibliografia que versasse especificamente da variação linguística nos livros didático da EJA.

Nos quatros volumes da Coleção Tempo de Aprender analisados percebe-se que há a abordagem da VL em apenas dois estudados: no Volumes I e III, expostos somente no Eixo da análise e da reflexão sobre a língua. No manual do professor (p.45) há a apresentação deste eixo, que é divido em duas seções "Um olhar para a língua" e "sua vez", menciona também que tais seções buscam possibilitar ao aluno aprimorar-se como usuário da língua, observando e testando as diferentes possibilidades de comunicação, o que corroborando com as ideias de Possenti (1996 apud Dionísio e Bezerra, 2005, p.88) “ [...] é no momento em que o aluno começa a reconhecer sua variedade linguística como uma variedade entre outras que ele ganha consciência de sua identidade linguística e se dispõe a observação das variedades que não domina."

No Volume I, para iniciar os estudos de VL, há a apresentação de parte do texto de Patativa do Assaré: Depoimento autobiográfico, na seção "Um olhar para a língua" intitulada Diferentes falares na página 26, há logo como primeiro questionamento se a fala apresentada no texto representa um jeito de falar típico de quem mantém a linguagem de homem do campo ou da cidade, esse é o principal problema encontrados no LD que é apontado por Bagno (2007, p.120):

Um dos principais problemas que encontramos nos livros didáticos é uma tendência de tratar a variação linguística como sinônimo de variedades regionais, rurais ou pessoas não escolarizadas. Parece está por trás dessa tendência a suposição (falsa) de que os falantes urbanos escolarizados usam a língua de um modo mais "correto", mas próximo do padrão, e que no uso que eles fazem não existe variação. 
Essa tendência é perceptível claramente na explicação dada sobre as variedades linguísticas encontradas no LD na seção “Você sabia?” tanto no volume I (página 27):

Mas a língua pode se manifestar em outras variedades, ou seja, outras maneiras de falar e escrever, diferentes da norma de prestígio e tão legítimas quanto ela. Por ser dinâmica, a língua passa por processo natural de mudança, variando na fala e na escrita, conforme o tempo em que se vive, lugar onde se mora, idade, sexo, grau de escolaridade, circunstancia em que a produzimos. A essas diferentes formas de falar e escrever, incluindo a norma urbana de prestígio, chamamos variedade linguísticas.

Quanto no volume II (p.16):

Em nossa sociedade há falares mais prestigiados e menos prestigiados. Damos o nome de norma urbana de prestígio aos falares urbanos que em uma comunidade linguística desfrutam de maior prestígio político, social e cultural. $\mathrm{O}$ uso da língua empregado por falantes cultos da área urbana costuma ser prestigiado socialmente, tanto na fala, quanto na língua.

Os trechos enfatizam que o fenômeno da VL caracterizaria somente os falares do campo. Essa aparição frequentemente nos LDLP, e como disse Bagno (2007), é muito comum a variação ser tratada como exclusividade de falantes rurais, como se só existisse variação ( isto é, no fim das contas, 'erro') nas falas dos 'caipiras' e 'matutos'. (grifos do autor)".

É inegável que há uma tentativa de se combater o preconceito linguístico e valorizar a multiplicidade linguística, perceptíveis em "diferentes da norma de prestígio e tão legitimas quanto ela” (LD, volume I, página 27). Contudo, Bagno (2007, p.119), ao se referir ao tratamento dado pelos LDs à Variação Linguistica, diz que é um tanto problemático, devido à falta de base teórica consistente dos autores, confusões de termos e dos conceitos são o que vem prejudicando o trabalho em torno dos fenômenos de variação e mudança.

No volume III, há, também na seção "Um olhar para a língua” intitulada Variedades Linguísticas, na página 15, uma atividade referente à análise da música "Cuitelinho" (de domínio público), questões que reafirmam um preconceito, já que solicitam que os alunos deêm significado à palavra "parentáia", ocorrendo o que normalmente acontece em geral, como afirmou Dionísio (2005, p.79): “no geral, os livros LDP focalizam a VL em exercícios relacionados com os textos utilizados, na seção destinada à compreensão, solicitando 
atividades de (i) identificação ... e (ii) reescritura", que neste caso aparece com a escrita do significado.

A abordagem da VL no LD em questão ocorre em uma unidade especifica no livro, em questões mínimas em análise textual e em seções sobre reflexão sobre a língua. Contudo, há atividades para serem feitas com as experiências vivenciadas pelos alunos, o que possibilita uma reflexão melhor da realidade linguística em que o estudante está inserido.

\section{CONCLUSÃO}

Levando em consideração o material analisado e referencial pesquisado ficou perceptível que os livros didáticos da EJA analisados, abordam a variação linguística com bastantes limitações no que se refere aos conceitos dos teóricos utilizados, visto que abordam a variação em capítulos específicos, havendo confusões de termos, além de não se referirem nem diferenciarem os conceitos sobre variação e mudança, e, principalmente porque apresentam indiretamente o preconceito quando enfatizam que a linguagem urbana é de prestígio e a linguagem rural é desprestigiada, como se no próprio meio urbano não ocorressem variações. Para melhor análise do uso de Variação Linguística em sala de aula, também é importante verificar: quais as concepções dos professores, a metodologia que aplicam, se são oportunizadas formações para trabalhar com o Livro Didático, ficando tais questionamentos, como sugestões, para serem investigados em outras pesquisas.

Assim, espera-se que as novas edições do PNLDEJA levem em consideração as concepções sociolinguísticas de variação e mudança, e que aos professores sejam oportunizados, se ainda não foram, formação para o trabalho adequado do livro didático.

\section{REFERÊNCIAS}

BAGNO, Marcos. Nada na língua é por acaso: por uma pedagogia da variação linguistica. São Paulo: Parábola, 2007.

;STUBBS, Michael; GAGNÉ, Gilles. Língua Materna: letramento, variação \& ensino. São Paulo: Parábola, 2002.

BORTONI-RICARDO, Stella Maris. Educação em língua materna: a sociolinguística na sala de aula. São Paulo: Parábola, 2004. 
Parábola, 2005.

Nós cheguemu na escola e agora? sociolinguística e educação. São Paulo:

BRASIL. Ministério da Educação. Lei de Diretrizes e Bases $n^{\circ} 9.394$, de 20 de dezembro de 1996. Disponível em: 〈http://www.planalto.gov.br/ccivil_03/Leis/L9394.htm>. Acessado em 18 de junho de 2018.

. Ministério da Educação. Diretrizes Curriculares Nacionais para a Educação de Jovens $e$ Adultos. Brasília: 2010. Disponível em: http://portal.mec.gov.br/secad/arquivos/pdf/eja/legislacao/parecer_11_2000.pdf Acessado em 18 de março de 2015.

Ministério da Educação. Decreto-Lei $n^{o}$ 5.692/71. Brasília, 1971. Disponível em: http://www.educacao.salvador.ba.gov.br/site/documentos/espaco-virtual/espacolegislacao/EDUCACIONAL/NACIONAL/ldb\%20n\%C2\%BA\%205692-1971.pdf Acessado em 18 de março de 2015.

Parecer 669/72. Brasília. 1972.

CALLOU, Dinah. Gramática, variação e mudança. In VIEIRA, Silvia Rodrigues; BRANDÂO, Silvia Figueredo (Orgs). Ensino de Gramática. São Paulo: Contexto, , 2007.p.13-54.

CARVALHO, Marlene. Primeiras letras: alfabetização de jovens e adultos em espaços populares. São Paulo: Ática, 2010.

DIONÍSIO, Ângela Paiva; BEZERRA, Maria Auxiliadora (orgs). O livro didático de português: múltiplos olhares. 2.ed. Rio de Janeiro: Lucerna, 2005.

FOUCAULT, Michel. Vigiar e punir: a história da violência nas prisões. Petrópolis: Vozes, 2009.

FREIRE, Paulo. Pedagogia da autonomia: saberes necessários à pratica docente. São Paulo, Paz e Terra, 1997.

. Pedagogia do Oprimido. Rio de Janeiro: Paz e Terra, 1988.

ILARI, Rodolfo; BASO, Renato. O português da gente: a língua que estudamos a língua que falamos. São Paulo: Contexto, 2006.

LAKA TOS, Eva Maria. Sociologia geral. 4. ed. São Paulo: Atlas, 1981.

; MARCONI, Marina de Andrade. Fundamentos de metodologia científica. 5ed. São Paulo: Atlas 2003.

MARQUES, Mario Osorio. Educação/Interlocução, Aprendizagem/Reconstrução de Saberes. Ijuí: Editora UNIJUI, 1996. 
Variação linguística nos livros didáticos de língua portuguesa da educação de jovens e adultos

MATTOS E SILVA. Rosa Virgínea. O português são dois: novas fronteiras, velhos problemas. São Paulo: Parábola, 2004.

MARCUSCHI, Luiz Antônio. Da fala para a escrita: atividades de retextualização. São Paulo: Cortez, 2001.

MUSSALIM, Fernanda; BENTES, Anna Christina (Orgs.). Introdução à linguística: domínios e fronteiras. V.1. São Paulo: Cortez, 2008.

PNLDEJA. Coleção Tempo de Aprender: Segundo segmento do ensino fundamental. Volume 1 e 3. São Paulo: IBEP, 2009. (manual do professor)

ROCHA, Raimundo Nonato Araújo da. A História ensinada para jovens e adultos pelos livros didáticos: uma análise dos livros aprovados pelo PNLDEJA/2011 para o segundo segmento do ensino fundamental. XXVII Simpósio Nacional de História, 2013. Disponível em:

http://www.snh2013.anpuh.org/resources/anais/27/1364957752_ARQUIVO_Textocompleto RaimundoNonatoAraujodaRocha1.pdf. Acesso em 19 de out. de 2018. 